\title{
Cycling kinematics in healthy adults for musculoskeletal rehabilitation guidance
}

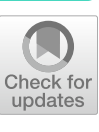

\author{
Haeun Yum ${ }^{1 \dagger}$, Hyang Kim² ${ }^{2 \dagger}$, Taeyong Lee ${ }^{1,3}$, Moon Seok Park ${ }^{4}$ and Seung Yeol Lee $5^{5^{*}}$
}

\begin{abstract}
Background: Stationary cycling is commonly used for postoperative rehabilitation of physical disabilities; however, few studies have focused on the three-dimensional (3D) kinematics of rehabilitation. This study aimed to elucidate the three-dimensional lower limb kinematics of people with healthy musculoskeletal function and the effect of sex and age on kinematics using a controlled bicycle configuration.

Methods: Thirty-one healthy adults participated in the study. The position of the stationary cycle was standardized using the LeMond method by setting the saddle height to $85.5 \%$ of the participant's inseam. The participants maintained a pedaling rate of $10-12 \mathrm{~km} / \mathrm{h}$, and the average value of three successive cycles of the right leg was used for analysis. The pelvis, hip, knee, and ankle joint motions during cycling were evaluated in the sagittal, coronal, and transverse planes. Kinematic data were normalized to 0-100\% of the cycling cycle. The Kolmogorov-Smirnov test, Mann-Whitney U test, Kruskal-Wallis test, and k-fold cross-validation were used to analyze the data.

Results: In the sagittal plane, the cycling ranges of motion (ROMs) were $1.6^{\circ}$ (pelvis), $43.9^{\circ}$ (hip), $75.2^{\circ}$ (knee), and $26.9^{\circ}$ (ankle). The coronal plane movement was observed in all joints, and the specific ROMs were $6.6^{\circ}$ (knee) and $5.8^{\circ}$ (ankle). There was significant internal and external rotation of the hip (ROM: $11.6^{\circ}$ ), knee (ROM: $6.6^{\circ}$ ), and ankle (ROM: $10.3^{\circ}$ ) during cycling. There was no difference in kinematic data of the pelvis, hip, knee, and ankle between the sexes $(p=0.12$ to 0.95 ) and between different age groups ( $p=0.11$ to 0.96 ) in all anatomical planes.
\end{abstract}

Conclusions: The kinematic results support the view that cycling is highly beneficial for comprehensive musculoskeletal rehabilitation. These results might help clinicians set a target of recovery ROM based on healthy and non-elite individuals and issue suitable guidelines to patients.

Keywords: Cycling kinematics, Musculoskeletal rehabilitation, Range of motion

\section{Background}

Musculoskeletal rehabilitation programs aim at comprehensive orthopedic rehabilitation post-surgery or injury. Rehabilitation helps patients regain muscle and joint function and restores bone health by building strength and restoring flexibility and mobility, which reduces pain.

\footnotetext{
*Correspondence: kernels00@naver.com

${ }_{5}^{\dagger}$ Haeun Yum and Hyang Kim contributed equally to this work.

${ }^{5}$ Department of Orthopaedic Surgery, Myongji Hospital, Hanyang

University College of Medicine, 55, Hwasu-ro 14beon-gil, Deogyang-gu, Goyang-si, Gyeonggi-do 10475, South Korea

Full list of author information is available at the end of the article
}

The bone strength and function of the joints declines with aging [1]; moreover, many countries have a high proportion of an aging population. Thus, musculoskeletal rehabilitation is of considerable importance.

Stationary cycling is commonly recommended for individuals with various disabilities, such as knee osteoarthritis and compromised function of the joints following surgeries like anterior cruciate ligament $(\mathrm{ACL})$ reconstruction and total hip arthroplasty. Cycling reduces the load on the knee joint $[2,3]$ and ACL [4-7]; the tibiofemoral compressive forces during cycling are between 0.3 and 2 times the body weight, while other full weight-bearing rehabilitative exercises 
(e.g., walking, stair ascent/descent) generate forces of approximately $2-4$ times the body weight $[4,8-10]$. The patellofemoral compressive force $[9,11]$, shear stress [12], tibiofemoral shear force [13, 14], and ACL strain $[9,11,15,16]$ are low during cycling; nevertheless, the quadriceps and hamstring muscles are strengthened as the knee stability increases [7, 12, 17-19]. Pedaling also increases the range of motion (ROM) of the hip, knee, and ankle joints [17, 20-23].

Many studies have investigated joint kinematics during cycling; however, most have been conducted on patients with orthopedic disabilities [12, 15, 24]. Few studies have investigated joint kinematics in healthy individuals. Furthermore, when healthy subjects were included in some of the studies, they were professional or experienced cyclists [25-28], and the study did not focus on target ROMs for rehabilitation purposes. Additionally, most studies analyzed the twodimensional kinematic data and focused on the sagittal plane joint kinematics during cycling [1]. The threedimensional (3D) kinematic data from individuals with healthy musculoskeletal function can serve as a clinical guide for appropriate cycling interventions, leading to more consistent results of the rehabilitation program. Therefore, this study aimed to elucidate 3D kinematics of the lower extremity joints in individuals with healthy musculoskeletal function and non-elite adults during cycling, and determine the kinematic differences by sex and age, and provide the literature on cycling rehabilitation.

\section{Methods}

This prospective study was approved by the institutional board of our hospital. Informed consent was obtained from all participants. All procedures were performed in accordance with the relevant guidelines.

We competitively recruited individuals aged $>18$ years (i.e., legal adults) through public notice or advertisement. Patients diagnosed with any musculoskeletal disease, those with a history of musculoskeletal trauma (including ligamentous injury and fracture), and those who were diagnosed with musculoskeletal deformities after the physical examination were excluded from the study. The participants were categorized into different age groups to determine the effects of age on kinematics. The categorization was group 1: <20years old, group 2: 21-35 years old, group 3: 36-50 years old, and group 4: $>50$ years old. The physical examination was performed by a surgeon with 14 years of experience in orthopedic practice.

\section{Measuring the kinematic data}

The bicycle settings can affect cycling performance. Thus, the position of each participant on the stationary cycle was standardized using the LeMond method, which is widely used and based on the empirical experience of the famous cyclist, Greg LeMond [29, 30]. The saddle height was measured from the center of the bottom bracket to the top of the seat along the seat tube. The saddle height was set at $88.3 \%$ of the distance between the highest point of one's inner thigh to the heel of one's foot, called an inseam (Fig. 1). This

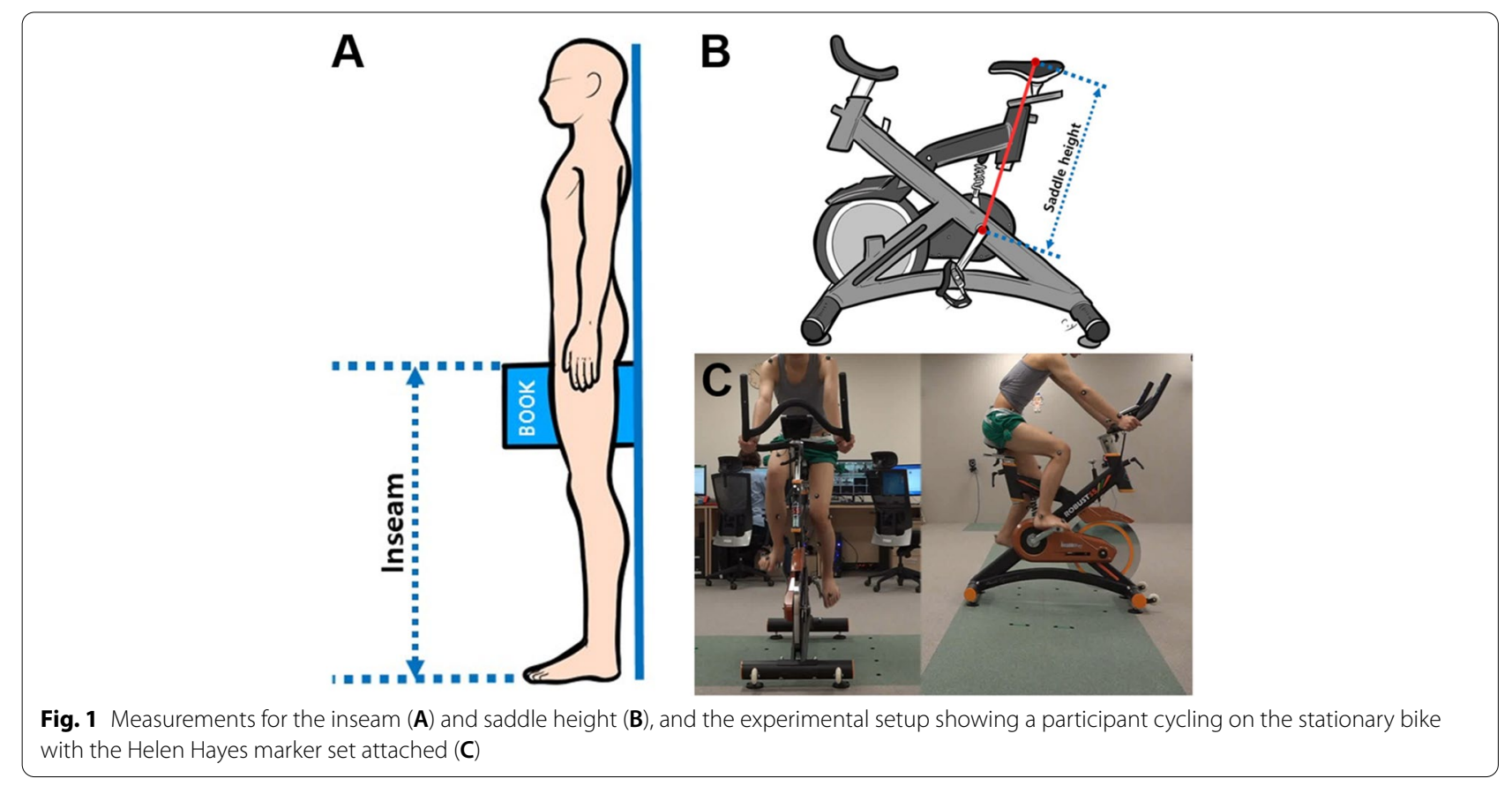


percentage is based on the average height of Westerners, and it is common to multiply the length by 0.855 for application to Asians [31]. Therefore, the configuration of the saddle height was set at $85.5 \%$ of the inseam in this study.

A pedaling rate of $10-12 \mathrm{~km} / \mathrm{h}$ was required throughout the test. To ensure that the rate was maintained, participants rode a bicycle ergometer (HealthWay, ROBUST $\mathrm{S} 5$, Korea) for several minutes before recording the kinematics. Data collection was started when the participants were acquainted with the speed and maintained a steady rate. We obtained the 3D kinematic data using a Kestrel Digital System (Motion Analysis, Rohnert Park, CA, USA) equipped with 10 cameras. The Helen Hayes marker set was used to place markers on the top, back, and front of the head; bilateral acromion and olecranon processes and both wrists, anterior superior iliac spine (ASIS), thigh wand, lateral epicondyle of femur, shank wand, lateral malleolus, posterior surface of calcaneus; space between the second and third metatarsal heads, and sacrum [32]. Three additional markers were attached. One was placed on the back for offset, and the remaining two markers were attached on both sides of the sacral marker to create markers in case the ASIS marker disappeared when riding the bike. The movements of the pelvis, hip, knee, and ankle joints during cycling were evaluated in the sagittal, coronal, and transverse planes. The kinematic data were normalized to $0-100 \%$ of the cycling session. The right pedal at $0^{\circ}$ was designated as $0 \%$, and the right pedal after one $360^{\circ}$ rotation (i.e., returned to $0^{\circ}$ ) was designated as $100 \%$. Based on clinical gait analysis studies that involve more heterogeneous motions than those when cycling, the average value of three successive cycles in the middle of the trail was used for analysis [33].

\section{Statistical analyses}

The lower extremity kinematics for the participants' right side were used for analysis to avoid duplication of demographics [34]. The Kolmogorov-Smirnov test was used to verify the normality of the distribution of continuous variables. Descriptive statistics (i.e., mean \pm standard deviation) were used to summarize the participants' demographic and kinematic data. Comparisons between male and female groups were made using the MannWhitney $U$ test based on data characteristics. The Kruskal-Wallis test was used to compare the kinematics between age groups. K-fold cross-validation was used to evaluate machine-learning models with a limited data sample. All statistical analyses were conducted using SPSS version 20.0 (IBM Co., Chicago, IL), and a $p$-value $<0.05$ was considered significant.

\section{Results}

Thirty-one participants were finally included in this study. The mean age at the time of examination was $35.0 \pm 13.8$ years (range, 18.2-68.1 years) (Table 1, Supplement 1). The mean saddle height was $68.0 \pm 1.7 \mathrm{~cm}$ (range, 64.9-72.2 cm) for men and 64.8 $\pm 1.1 \mathrm{~cm}$ (range, $63.4-66.2 \mathrm{~cm}$ ) for women (Table 1).

The joint motions were observed in all three planes (Table 2, Fig. 2). During cycling, the pelvis moved very little in the sagittal plane. The ROMs were $43.9 \pm 3.7^{\circ}$ (hip), $75.2 \pm 7.2^{\circ}$ (knee), and $26.9 \pm 10.5^{\circ}$ (ankle). The movement in the coronal plane was observed in all joints; particularly, the knee ROM was $6.6 \pm 2.7^{\circ}$, and the ankle $\mathrm{ROM}$ was $5.8 \pm 3.2^{\circ}$. The movement in the transverse plane was also observed in all the major joints of the lower extremity. Internal and external rotation occurred in the hip $\left(11.6 \pm 4.5^{\circ}\right)$, ankle $\left(10.3 \pm 4.9^{\circ}\right)$, and mainly in the knee joints $\left(6.6 \pm 2.7^{\circ}\right)$.

The kinematic data of the pelvis, hip, knee, and ankle joints did not differ between the sexes ( $p=0.12$ to 0.95$)$ or between the different age groups $(p=0.11$ to 0.96$)$ in all anatomical planes. In $\mathrm{k}$-fold cross-validation of the age groups, the area under the curve was between 0.475 and 0.610 .

\section{Discussion}

Cycling is one of the most effective orthopedic rehabilitation methods to recover joint ROM with less weight load. Most studies have examined cycling in two dimensions, especially the sagittal plane $[21,35,36]$; however, recent studies have indicated that movements in the coronal and transverse also occur during cycling $[1,11,27]$. In recent times, 3D motion analysis is becoming critical for assessing the full rehabilitation potential. Thus, this

Table 1 Patient demographics

\begin{tabular}{ll}
\hline Parameter & Value \\
\hline No. of subjects (Male/Female) & $31(23 / 8)$ \\
Age & $35.0 \pm 13.8(18.2-68.1)$ \\
Height & $172.1 \pm 5.1(162.9-185.0)$ \\
$\quad$ Male & $174.1 \pm 4.2(166.8-185.0)$ \\
$\quad$ Female & $166.5 \pm 2.9(162.9-170.0)$ \\
Inseam & $78.5 \pm 2.4(74.2-84.5)$ \\
$\quad$ Male & $79.5 \pm 1.9(75.9-84.5)$ \\
Female & $75.8 \pm 1.3(74.2-77.4)$ \\
Saddle height & $67.1 \pm 2.1(63.4-72.2)$ \\
$\quad$ Male & $68.0 \pm 1.7(64.9-72.2)$ \\
Female & $64.8 \pm 1.1(63.4-66.2)$ \\
\hline
\end{tabular}

Age, Height, Inseam, and Saddle height; mean \pm standard deviation (range) Age $=$ decimal years

Saddle height $=$ inseam $\times 0.855$ 
Table 2 Sagittal, coronal, and transverse plane kinematics of the lower extremity during cycling

\begin{tabular}{|c|c|c|c|c|}
\hline & & Range of motion (•) & & Maximum value $(\bullet)$ \\
\hline \multirow[t]{8}{*}{ Sagittal plane } & Pelvis & $\begin{array}{l}1.6 \pm 0.6 \\
(0.7-3.6)\end{array}$ & Posterior tilt & $\begin{array}{l}-15.0 \pm 3.5 \\
(-24.1--7.7)\end{array}$ \\
\hline & & & Anterior tilt & $\begin{array}{l}16.6 \pm 3.6 \\
(8.9-25.3)\end{array}$ \\
\hline & Hip & $\begin{array}{l}43.9 \pm 3.7 \\
(36.7-51.5)\end{array}$ & Extension & $\begin{array}{l}-43.0 \pm 5.1 \\
(-54.4--34.5)\end{array}$ \\
\hline & & & Flexion & $\begin{array}{l}86.9 \pm 4.3 \\
(79.7-98.0)\end{array}$ \\
\hline & Knee & $\begin{array}{l}75.2 \pm 7.2 \\
(60.1-94.1)\end{array}$ & Extension & $\begin{array}{l}-34.0 \pm 9.8 \\
(-57.2--14.7)\end{array}$ \\
\hline & & & Flexion & $\begin{array}{l}109.3 \pm 3.9 \\
(102.7-118.5)\end{array}$ \\
\hline & Ankle & $\begin{array}{l}26.9 \pm 10.5 \\
(10.8-47.0)\end{array}$ & Dorsiflexion & $\begin{array}{l}7.6 \pm 8.1 \\
(-6.2-28.3)\end{array}$ \\
\hline & & & Plantar flexion & $\begin{array}{l}19.2 \pm 7.6 \\
(1.6-31.8)\end{array}$ \\
\hline \multirow[t]{8}{*}{ Coronal plane } & Pelvis & $\begin{array}{l}7.1 \pm 2.5 \\
(2.0-11.7)\end{array}$ & Rt side up & $\begin{array}{l}3.5 \pm 2.1 \\
(-1.2-7.2)\end{array}$ \\
\hline & & & Rt side down & $\begin{array}{l}3.6 \pm 2.4 \\
(-1.1-7.8)\end{array}$ \\
\hline & Hip & $\begin{array}{l}5.0 \pm 1.8 \\
(1.6-10.8)\end{array}$ & Adduction & $\begin{array}{l}10 \pm 3.4 \\
(5.9-21.8)\end{array}$ \\
\hline & & & Abduction & $\begin{array}{l}-5.1 \pm 2.9 \\
(-13.6--0.9)\end{array}$ \\
\hline & Knee & $\begin{array}{l}6.6 \pm 2.7 \\
(2.5-12.0)\end{array}$ & Varus & $\begin{array}{l}1.6 \pm 2.8 \\
(-4.2-6.44)\end{array}$ \\
\hline & & & Valgus & $\begin{array}{l}5.0 \pm 2.2 \\
(0.3-9.2)\end{array}$ \\
\hline & Ankle & $\begin{array}{l}5.8 \pm 3.2 \\
(2.1-14.2)\end{array}$ & Inversion & $\begin{array}{l}1.5 \pm 6.0 \\
(-14.1-13.0)\end{array}$ \\
\hline & & & Eversion & $\begin{array}{l}4.3 \pm 6.5 \\
(-10.2-20.6)\end{array}$ \\
\hline \multirow[t]{8}{*}{ Transverse plane } & Pelvis & $\begin{array}{l}3.2 \pm 1.9 \\
(0.9-8.7)\end{array}$ & Internal ROT & $\begin{array}{l}2.4 \pm 3.1 \\
(-4.2-8.8)\end{array}$ \\
\hline & & & External ROT & $\begin{array}{l}0.8 \pm 3.3 \\
(-4.3-12.5)\end{array}$ \\
\hline & Hip & $\begin{array}{l}11.6 \pm 4.5 \\
(3.3-23.8)\end{array}$ & Internal ROT & $\begin{array}{l}6.3 \pm 3.5 \\
(-0.0-13.7)\end{array}$ \\
\hline & & & External ROT & $\begin{array}{l}5.3 \pm 6.1 \\
(-5.9-20.6)\end{array}$ \\
\hline & Knee & $\begin{array}{l}6.6 \pm 2.7 \\
(2.5-12.0)\end{array}$ & Internal ROT & $\begin{array}{l}5.0 \pm 2.2 \\
(0.3-9.2)\end{array}$ \\
\hline & & & External ROT & $\begin{array}{l}1.6 \pm 2.8 \\
(-4.2-6.4)\end{array}$ \\
\hline & Ankle & $\begin{array}{l}10.3 \pm 4.9 \\
(3.9-22.0)\end{array}$ & Internal ROT & $\begin{array}{l}4.4 \pm 5.1 \\
(-5.7-18.9)\end{array}$ \\
\hline & & & External ROT & $\begin{array}{l}6.0 \pm 4.3 \\
(-1.0-13.2)\end{array}$ \\
\hline
\end{tabular}

Rt Right, ROT Rotation

study evaluated the 3D lower limb kinematics of people with healthy musculoskeletal function during stationary cycling and aimed to provide guidance for a target recovery ROM for physical rehabilitation. This study showed that considerable movement occurs in the sagittal plane and in the coronal and transverse planes. We also found that customizing the saddle height leads to constant joint kinematics.

The saddle position is often selected based on comfort. An improper position can lead to knee joint overuse 


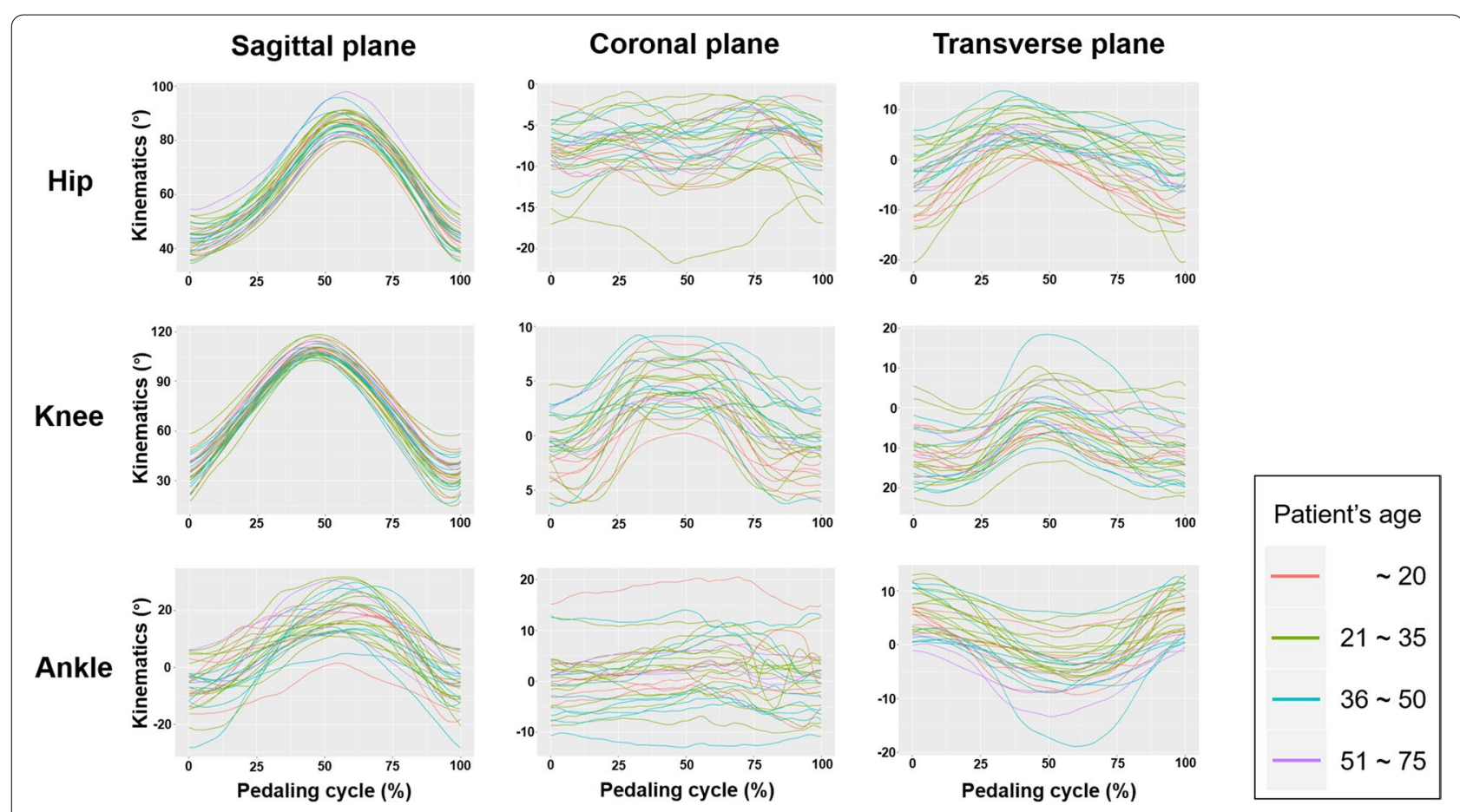

Fig. 2 Hip, knee, and ankle joint angles for one complete revolution $\left(0^{\circ}-360^{\circ}\right)$ of the bicycle crank for each participant's right leg in the sagittal, coronal, and transverse planes

injuries [2, 35, 37-39] and inconsistent kinematics. Numerous methods have been proposed to determine the appropriate saddle height configuration [11]. We selected the LeMond method since it is common, reliable [37], and simple to apply, which is important because most patients use public bicycles in clinics for rehabilitation purposes rather than personal bicycles. We adjusted the saddle height to the length of each participant's inseam, considering the Asian-specific multiplication ratio. To our knowledge, this is the first study that considered the cycling rehabilitation environment based on race and individuals.

We found sagittal, coronal, and transverse movements in all joints during standardized ergometer cycling, enabling comprehensive rehabilitation guidance. When the sagittal joint ROMs obtained during ergometer cycling were compared with the mean values of normal ROMs, the hip ROM was approximately $31 \%$, the knee ROM was approximately $54 \%$, and the ankle ROM was approximately $42 \%$ of normal [7, 40-45] (Fig. 3). The cycling kinematics of the lower limb joints were also compared to normal walking kinematics. The normal sagittal plane ROM during a human gait cycle is approximately $45^{\circ}$ in the hip (ranging from $10^{\circ}$ [extension] to $35^{\circ}$ [flexion]), $55^{\circ}$ in the knee (ranging from $5^{\circ}$ [flexion] to $60^{\circ}$ [flexion]), and $30^{\circ}$ in the ankle (ranging from $15^{\circ}$ [dorsiflexion] to $15^{\circ}$ [plantarflexion]) $[46,47]$. This indicates that the hip and knee joints were much more flexed during cycling and that the ankle joint motion was similar to that during walking. The overall joint motion during pedaling might not have an advantage over that during walking. However, the range of angles in which the joint motion occurred during cycling was different from that during walking; this suggests that pedaling has effects that cannot be achieved only by walking. Thus, in terms of kinematics, cycling for musculoskeletal rehabilitation is highly recommended. Cycling could recover a partial ROM, and additional rehabilitative exercise is necessary to restore the ROM that cannot be recovered by cycling. In addition to walking, various other exercises could be included and cycling could be one. Lower limb kinematics are influenced by the saddle height $[7,11,26]$. Thus, the hip, knee, and ankle joint motions can be adjusted by changing the saddle height. For example, more plantar flexion can be achieved by increasing the saddle height. Further investigations are necessary to determine how cycling ROMs could be broadened for rehabilitation.

For the knee and ankle joints, significant internal and external rotation and coronal plane movements were observed. Cycling is recommended for individuals with knee disabilities because it exerts less weight on the knee [4]. However, cycling considerably rotates the knee, which should be considered before initiating bicycle rehabilitation for injuries adversely affected by rotational 


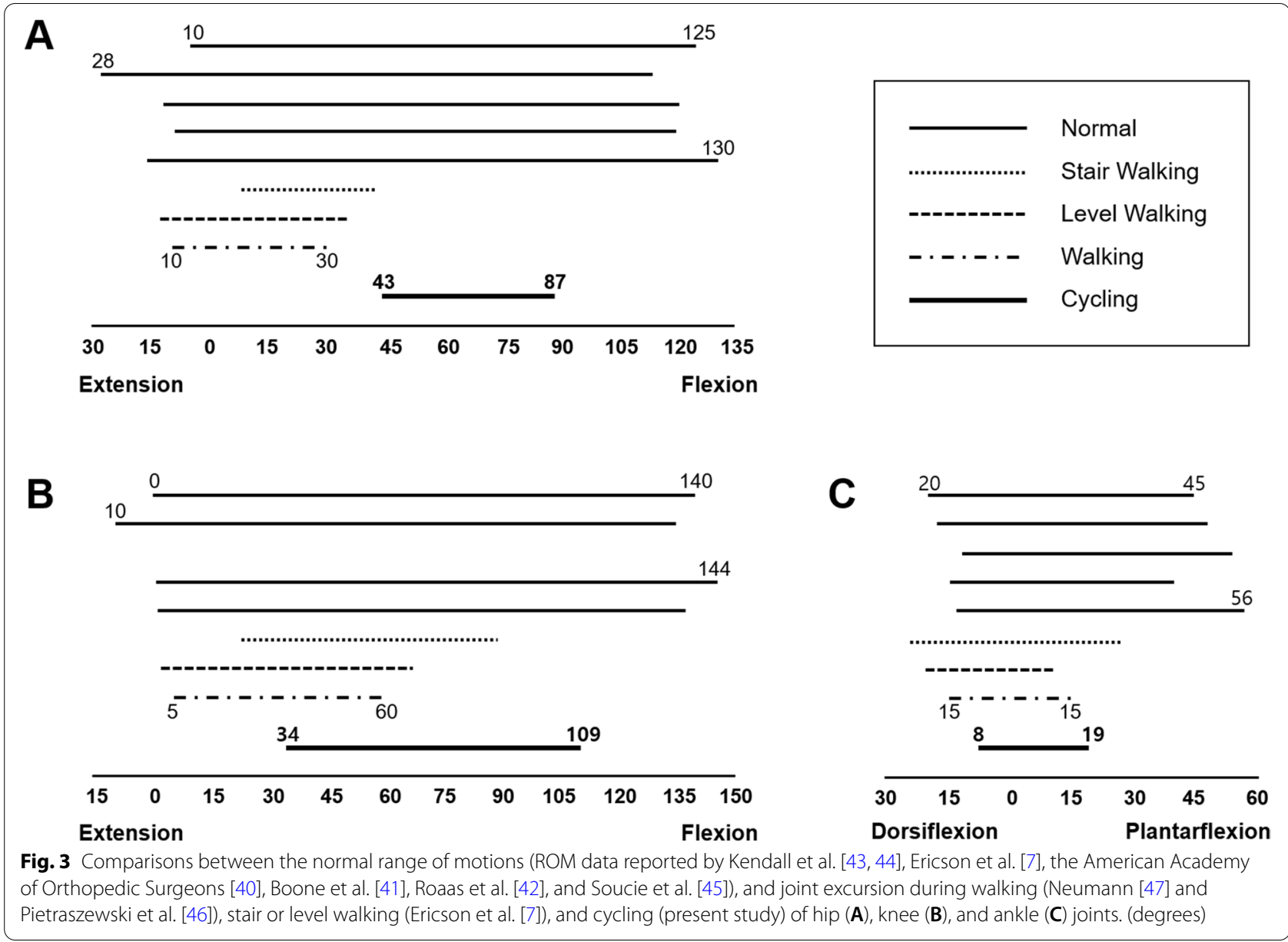

motion, such as meniscus and ankle ligament injuries. Understanding the 3D joint kinematics in healthy and normal individuals might help clinicians plan a target recovery ROM and issue guidance to patients.

This study attempted to recruit adult patients across all age groups for comparison according to sex and 10-year age groups. Pelvis, hip, knee, and ankle joint kinematics did not differ between the sexes or between age groups, indicating that customizing the saddle height per individual results in constant kinematics regardless of sex and age. No studies have investigated the effects of sex and age on joint kinematics in the context of rehabilitation. Thus, these results provide a good reference for planning lower limb rehabilitation.

There were a few limitations in this study. First, there were a small number of participants. This was a pilot study in preparation for a large sample size study, and to overcome the small sample size, additional k-fold crossvalidation was conducted. Second, the saddle height was set considering an empirical percentage for leg length ( 0.855 for Asians), and the bicycle configuration did not consider the handlebar position. Comparative research is necessary to determine whether other bicycle configurations have an effect on joint ROM or rehabilitation.

\section{Conclusions}

This study found that stationary cycling generates movement in the sagittal, coronal, and transverse planes, facilitating comprehensive lower limb rehabilitation. The findings can serve as a guide for setting the target kinematics during musculoskeletal rehabilitation with a stationary bicycle for individuals with orthopedic disabilities. The saddle height was adjusted for each participant; this led to consistent joint motions. Given the limited number of studies on bicycle 3D movement among the general population (non-professional athletes), further work is warranted to determine a suitable ROM for cycling rehabilitation customizable according to the race and physical conditions.

\section{Abbreviations}

3D: Three-dimensional; ROM: Range of motion; ACL: Anterior cruciate ligament; Rt: Right; ROT: Rotation. 


\section{Supplementary Information}

The online version contains supplementary material available at https://doi. org/10.1186/s12891-021-04905-2.

Additional file 1: Supplement 1. Subjects'data.

\section{Acknowledgements \\ Not applicable.}

\section{Authors' contributions}

All authors (HY, HK, TL, MSP, and SYL) in this manuscript made significant contributions to the study design. HY and SYL analyzed and interpreted the data, and wrote the article, and approved the final version of the manuscript. HK and MSP acquired and analyzed the data. TL helped to draft the manuscript and critically revised the manuscript. All authors have read and approved the final version of the manuscript.

\section{Funding}

This research was supported by the Basic Science Research Program through the National Research Foundation of Korea (NRF) funded by the Ministry of Science and ICT (NRF-2019R1A2C2010150). This funding source had no role in the design of this study and will not have any role during its execution, analyses, interpretation of the data, or decision to submit results.

\section{Availability of data and materials}

The datasets used and/or analyzed during this study are available from the corresponding author on reasonable request.

\section{Declarations}

\section{Ethics approval and consent to participate}

Seoul National University Bundang Hospital Institutional Review Board in Seongnam, Korea approved the study protocol. (IRB No: B-2103/673-107). Informed consent was obtained from all participants.

\section{Consent for publication}

Not applicable.

\section{Competing interests}

The authors declare that they have no competing interests.

\section{Author details}

${ }^{1}$ Division of Mechanical and Biomedical Engineering, Ewha Womans University, Seoul, South Korea. ${ }^{2}$ New Horizon Biomedical Engineering Institute, Myongji Hospital, Goyang, Gyeonggi-do, South Korea. ${ }^{3}$ Graduate Program in System Health Science and Engineering (BK21 Plus Program), Ewha Womans University, Seoul, South Korea. ${ }^{4}$ Department of Orthopaedic Surgery, Seoul National University Bundang Hospital, Seongnam, Gyeonggi-do, South Korea. ${ }^{5}$ Department of Orthopaedic Surgery, Myongji Hospital, Hanyang University College of Medicine, 55, Hwasu-ro 14beon-gil, Deogyang-gu, Goyang-si, Gyeonggi-do 10475, South Korea.

Received: 18 May 2021 Accepted: 23 November 2021

Published online: 15 December 2021

\section{References}

1. Johnston TE. Biomechanical considerations for cycling interventions in rehabilitation. Phys Ther. 2007;87:1243-52.

2. Gardner JK, Klipple G, Stewart C, Asif I, Zhang S. Acute effects of latera shoe wedges on joint biomechanics of patients with medial compartment knee osteoarthritis during stationary cycling. J Biomech. 2016:49:2817-23.

3. Wang Y, Liang L, Wang D, Yunqi T, Wu X, Li L, et al. Cycling with low saddle height is related to increased knee adduction moments in healthy recreational cyclists. Eur J Sport Sci. 2019;20:1-19.
4. Ericson MO, Nisell R. Tibiofemoral joint forces during ergometer cycling. Am J Sports Med. 1986;14:285-90.

5. Reiser R, Broker J, Peterson M. Knee loads in the standard and recumbent cycling positions. Biomed Sci Instrum. 2004;40:36-42.

6. Fleming BC, Beynnon BD, Renstrom PA, Peura GD, Nichols CE, Johnson $\mathrm{RJ}$. The strain behavior of the anterior cruciate ligament during bicycling. Am J Sports Med. 1998;26:109-18.

7. Ericson MO, Nisell R, Németh G. Joint motions of the lower limb during ergometer cycling. J Orthop Sports Phys Ther. 1988:9:273-8.

8. D'Lima DD, Patil S, Steklov N, Slamin JE, Colwell CW Jr. The Chitranjan Ranawat award: in vivo knee forces after total knee arthroplasty. Clin Orthop Relat Res. 2005:440:45-9.

9. Neptune RR, Kautz SA. Knee joint loading in forward versus backward pedaling: implications for rehabilitation strategies. Clin Biomech (Bristol, Avon). 2000;15:528-35.

10. Pottinger MV. Inverse dynamic analysis of acl reconstructed knee joint biomechanics during gait and cycling using OpenSim. https://digit alcommons.calpoly.edu/theses/1988/. Accessed 15 Oct 2020; 2018.

11. Bini R, Hume PA, Croft JL. Effects of bicycle saddle height on knee injury risk and cycling performance. Sports Med. 2011;41:463-76.

12. Shelbourne KD, Nitz P. Accelerated rehabilitation after anterior cruciate ligament reconstruction. Am J Sports Med. 1990;18:292-9.

13. Greca JPA, Ryan J, Baltzopoulos V, Korff T. Biomechanical evaluation of walking and cycling in children. J Biomech. 2019;87:13-8.

14. Palumbieri A. Comparative analysis of models for the assessment of tibiofemoral contact loads during cycling and gait trials; 2019. https:// www.politesi.polimi.it/handle/10589/150141. Accessed 21 Oct 2020

15. Eisner WD, Bode SD, Nyland J, Caborn DNM. Electromyographic timing analysis of forward and backward cycling. Med Sci Sports Exerc. 1999;31:449-55.

16. Johnston TE, Baskins TA, Koppel RV, Oliver SA, Stieber DJ, Hoglund LT. The influence of extrinsic factors on knee biomechanics during cycling: a systematic review of the literature. Int J Sports Phys Ther. 2017; 12:1023.

17. Komiyama K, Hamai S, Ikebe S, Yoshimoto K, Higaki H, Shiomoto K, et al. In vivo kinematic analysis of replaced hip during stationary cycling and computer simulation of optimal cup positioning against prosthetic impingement. Clin Biomech. 2019;68:175-81.

18. Mador MJ. Exercise training in patients with COPD - one leg is better than two? Chest. 2008;133:337-9.

19. Olivier N, Weissland T, Legrand R, Berthoin S, Rogez J, Thevenon A, et al. The effect of a one-leg cycling aerobic training program during the rehabilitation period in soccer players with anterior cruciate ligament reconstruction. Clin J Sport Med. 2010;20:28-33.

20. Houtz SJ, Fischer FJ. An analysis of muscle action and joint excursion during exercise on a stationary bicycle. J Bone Jt Surg. 1959;41:123-31.

21. Hubley CL, Kozey JW, Stanish WD. The effects of static stretching exercises and stationary cycling on range of motion at the hip joint. J Orthop Sports Phys Ther. 1984:6:104-9.

22. Smith-Petersen MN. Arthroplasty of the hip: a new method. J Bone Jt Surg. 1939;21:269-88

23. Hutchison R, Myers J, Hayden N, Shearer L, Bruneau K, DesJardins JD. Evaluation of isokinetic single-leg cycling as a rehabilitation exercise following anterior cruciate ligament reconstruction surgery. J Funct Morphol Kinesiol. 2017:2:32.

24. Gardner JK, Zhang S, Liu H, Klipple G, Stewart C, Milner CE, et al. Effects of toe-in angles on knee biomechanics in cycling of patients with medial knee osteoarthritis. Clin Biomech. 2015:30:276-82.

25. Barratt PR, Martin JC, Elmer SJ, Korff T. Effects of pedal speed and crank length on pedaling mechanics during submaximal cycling. Med Sci Sports Exerc. 2016:48:705-13.

26. Ferrer-Roca V, Roig A, Galilea P, García-López J. Influence of saddle height on lower limb kinematics in well-trained cyclists: static vs. dynamic evaluation in bike fitting. J Strength Cond Res. 2012;26:3025-9.

27. Sinclair J, Hebron J, Atkins S, Hurst H, Taylor P. The influence of 3D kinematic and electromyographical parameters on cycling economy. Acta Bioeng Biomech. 2014;16:91-7.

28. Bini RR, Dagnese F, Rocha E, Silveira MC, Carpes FP, Mota CB. Threedimensional kinematics of competitive and recreational cyclists across different workloads during cycling. Eur J Sport Sci. 2016;16:553-9.

29. Burke E. Serious cycling 2nd edition. Champaign: Human Kinetics; 2002 
30. Burke E. High-tech cycling. Champaign: Human Kinetics; 2003.

31. Shon G-H. Bike fitter manual. Seoul: Dae Keoung Books; 2014.

32. Kim H-J, Chun H-J, Shen F, Kang K-T, Chang B-S, Lee C-K, et al. Analysis of pelvic compensation for dynamic sagittal imbalance using motion analysis. Eur Spine J. 2020;29:428-37.

33. Lee SY, Kwon S-S, Chung CY, Lee KM, Choi Y, Kim TG, et al. Rectus femoris transfer in cerebral palsy patients with stiff knee gait. Gait Posture. 2014;40:76-81.

34. Park MS, Kim SJ, Chung CY, Choi IH, Lee SH, Lee KM. Statistical consideration for bilateral cases in orthopaedic research. J Bone Joint Surg Am. 2010;92:1732-7.

35. Bini R, Daly L, Kingsley M. Changes in body position on the bike during seated sprint cycling: applications to bike fitting. Eur J Sport Sci. 2020;20:35-42.

36. Bini R, Jacques T, Lanferdini F, Vaz M. Comparison of kinetics, kinematics, and electromyography during single-leg assisted and unassisted cycling. J Strength Cond Res. 2015;29:1534-41.

37. Swart J, Holliday W. Cycling biomechanics optimization-the ( $r$ ) evolution of bicycle fitting. Curr Sports Med Rep. 2019;18:490-6.

38. Bini RR, Flores BA. Potential factors associated with knee pain in cyclists: a systematic review. Open Access J Sports Med. 2018;9:99-106.

39. Menard M, Domalain M, Decatoire A, Lacouture P. Influence of saddle setback on knee joint forces in cycling. Sports Biomech. 2018;19:245-57.

40. American Academy of Orthopaedic S. Joint motion: method of measuring and recording. Chicago: American Academy of Orthopaedic Surgeons; 1965

41. Boone DC, Azen SP. Normal range of motion of joints in male subjects. J Bone Joint Surg Am. 1979;61:756-9.

42. Roaas A, Andersson GB. Normal range of motion of the hip, knee and ankle joints in male subjects, 30-40 years of age. Acta Orthop Scand. 1982:53:205-8

43. Kendall HO, Kendall FP, Wadsworth GE. Muscles, testing and function. Philadelphia: Williams and Wilkins; 1971.

44. Roach KE, Miles TP. Normal hip and knee active range of motion: the relationship to age. Phys Ther. 1991;71:656-65.

45. Soucie JM, Wang C, Forsyth A, Funk S, Denny M, Roach KE, et al. Range of motion measurements: reference values and a database for comparison studies. Haemophilia. 2011;17:500-7.

46. Pietraszewski B, Winiarski S, Jaroszczuk S. Three-dimensional human gait pattern - reference data for normal men. Acta Bioeng Biomech. 2012;14:9-16.

47. Neumann DA. Kinesiology of the musculoskeletal system : foundations for physical rehabilitation. St. Louis: Mosby/Elsevier; 2010.

\section{Publisher's Note}

Springer Nature remains neutral with regard to jurisdictional claims in published maps and institutional affiliations.

Ready to submit your research? Choose BMC and benefit from:

- fast, convenient online submission

- thorough peer review by experienced researchers in your field

- rapid publication on acceptance

- support for research data, including large and complex data types

- gold Open Access which fosters wider collaboration and increased citations

- maximum visibility for your research: over $100 \mathrm{M}$ website views per year

At $\mathrm{BMC}$, research is always in progress.

Learn more biomedcentral.com/submissions 